\title{
LA ETAPA ARGENTINA EN LA POESÍA DE RAFAEL ALBERTI
}

Vicente Granados

U.N.E.D.

Vuelva a mí toda virgen la palabra precisa.

R. A.

La etapa argentina está marcada primero por la provisionalidad y luego por la nostalgia ${ }^{1}$. Sin embargo, pronto abandona la línea de Vida bilingüe...; aquella confusión queda en el olvido, y ahora se replantea la creación poética en el prólogo de Entre el clavel y la espada 2 :

Después de este desorden impuesto, de esta prisa, de esta urgente gramática necesaria en que vivo, vuelva a mi toda virgen la palabra precisa, virgen el verbo exacto con el justo adjetivo.

Que cuando califique de verde al monte, al prado, repitiéndole al cielo su azul como a la mar, mi corazón se sienta recién inaugurado $v$ mi lengua el inédito asombro de crear.

Por otra parte, en el segundo prólogo del mismo libro (esta vez en prosa), alude al compromiso político y al amor: «Hincado entre los dos vivimos: de un lado, un seco olor a sangre pisoteada; de

1 Sobre los conceptos de nostalgia y futuro en la poesía albertiana, escribí extensamente en la revista Argumentos, número 55-56, 1983.

2 Obra escrita entre 1939 y 1940 . Publicada en 1941. 
otro, un aroma a jardines, a amanecer diario, a vida fresca, fuerte, inexpugnable.» Pero es la reflexión sobre la creación poética la que da unidad al libro. La primera pieza de la sección "Sonetos corporales» (clara réplica al título juanramoniano "Sonetos espirituales») describe el acto fisiológico del nacimiento, pero "está presente también el significado metafórico: el poeta, liberado ya de la sangre y del sufrimiento (...) aspira a empaparse nuevamente de luz $y$, por tanto, a iluminar de acuerdo con su misión. Situado "entre el clavel y la espada», Alberti escogerá definitivamente el clavel, la belleza autónoma del arte, y sus incursiones en la poesía militante - las Coplas de Juan Panadero, por ejemplo- serán, a partir de ahora, circunstanciales y esporádicas» ${ }^{3}$. El nacimiento -dolor y luz de la criatura - corre paralelo al nacimiento poético:

Lloraba recio, golpeando, oscuro, las humanas paredes sin salida...

Para marcarlo de una sacudida, lo esperaba la luz fuera del muro.

Grito en la entraña que lo hincó, futuro, desventuradamente y resistida por la misma cerrada, abierta herida que ha de exponerlo al primer golpe duro.

¡Qué desconsolación y qué ventura! Monstruo batido en sangre, descuajado de la cueva carnal del sufrimiento.

Mama la luz y agótala, criatura, tabicala en tu ser iluminado, que mamas con la leche el pensamiento.

Pocos textos albertianos encontramos donde se refleje con tanta ansia la ilusión creadora. El objetivo de nuestro poeta es producir una obra que, originándose en él, se origine frente a él. "Cada ser es un monstruo porque es inexplicable, extraño, absurdo. (Es el valor primordial que monstrum tenía en latín) ${ }^{4}$.

Pero en el soneto transcrito el poeta se asombra -casi diríamos se asusta- ante la creación: "¡Qué desconsolación y qué ventura!"

3 Senabre, Ricardo: La poesia de Rafael Alberti, Universidad de Salamanca, 1977, pág. 76. Sin embargo, Alberti prolonga hasta ahora las Coplas de Juan Panadero: «La voz de este Juan de la calle me hace falta, y habrá siempre que recurrir a ella mientras el pueblo se llame Juan y reclame de sus coplas ese sentido justiciero que nunca deja de cantar en ellas.» Vid. edición española de las Coplas..., Madrid, ed. Mayoria, 1977.

4 Alonso, Dámaso: Prólogo de Hijos de la ira, Barcelona, Labor, edición de Elias L. Rivers, 1970, pág. 30. Don Dámaso se refiere a su propia obra. 
Dicho de otra forma: Alberti no quiere romper el mundo poético, sino rehacerlo hasta el origen:

Mama la luz y agótala, criatura, tabicala en tu ser iluminado.

¿Cómo explicarse esas criaturas monstruosas que son los poemas? Alberti renuncia a ello y sólo quiere tabicar la luz: la cultura o el poema no son naturaleza, sino organización. Nuestro poeta se busca a sí mismo en las criaturas que ha compuesto, pero ellas no son su reflejo: el desconcierto otra vez. Alberti, por otra parte, ha vivido - vive- en un tiempo que le arrebatará todas las cosas en las que cree. Por eso su obra -incluso la más comedida aparentemente - es un grito a contracorriente. Cada escritor puede oponerse al presente mostrenco y manifestarse contra él. La oposición puede ser política y/o literaria; en el último caso suele tomar dos direcciones que no son excluyentes: una literatura cívica $o$, simplemente, una creación que vuelva la espalda a la realidad. Los ejemplos de este último caso abundan en nuestra historia contemporánea, sobre todo en la etapa que se inaugura con la Restauración: desde la obra de Juan Ramón Jiménez (horrorizado ante la mediocridad burguesa) a las Sonatas valleinclanescas o las novelas mironianas, incomprendidas por teóricos de la burguesía como Ortega. Pero está claro que no es lo mismo «elegir la forma» que decidir actuaciones: ese es el drama de Entre el clavel y la espada, cuya tercera parte se agrupa bajo un título muy significativo: «Metamorfosis del clavel». La metamorfosis se disfraza a veces de recuerdos infantiles («junto a la mar y un río y en mis primeros años, / quería ser caballo»), pero la tragedia más honda reside en los animales que equivocan su destino:

El caballo pidió sábanas,

rizadas como los rios.

Sábanas blancas.

Quiero ser hombre una noche.

Llamadme al alba.

La mujer no lo llamó.

(Nunca más volvio a su cuadra.)

Quizá el poema más conocido de esta sección es el que empieza así: «Se equivocó la paloma, / se equivocaba.» Marina Mayoral ha observado que «esos versos hacen alusión a una de las más 
horribles catástrofes que pueden suceder a la humanidad: la destrucción del instinto (...). "Se equivocó la paloma» está aludiendo a este tipo de realidad: a la destrucción de las leyes naturales, al error del instinto, a la equivocación de lo que no debe equivocarse jamás, so pena de caer en el caos y en el desorden absoluto" 5 . Además, en la "Metamorfosis del clavel" nos encontramos con que la vaca quiere ser mujer, la yerba - si crece- puede Ilamarse cabello.

Aunque Entre el clavel y la espada se escribe en unos años en que el mundo temía el descubrimiento de nuevas armas aniquiladoras, creo que las metamorfosis a las que me estoy refiriendo son simplemente poéticas. El poeta es un prometeo y sus criaturas lo devoran y le arrancan nuevos poemas. Pero no olvidemos la declaración de principios: "Vuelva a mí toda virgen la palabra precisa.» En ese forcejeo por encontrar «la palabra precisa» se tropieza con el artificio que tantas veces nos desorienta: no existe el poema como simple reflejo del autor, sino que éste se convierte en reflejo gestante de su criatura:

\section{Mamaba el toro, mamaba \\ la leche de la serrana. \\ Al toro se le ponian ojos de muchacha. \\ Ya que eres toro, mi hijo, dame una cornada. \\ Verás que tengo otro toro entre las entrañas.}

(La madre se volvio yerba, $y$ el toro, toro de agua.)

Te metí desde nifno, chica mar, en mi frente. R. A.

Alberti nació en «uno de esos blancos puertos que se asoman a la perfecta bahía gaditana». Conscientemente o no delimita al mar: no se trata de esa masa abierta y caótica, sino concretísima;

5 Mayoral, Marina: Poesía española contemporanea, Madrid, Gredos, 1973, págs. 180-181. 
calificada con el adjetivo que indica el mayor grado de bondad o excelencia: perfecta. Así, en Pleamar el mar no es lo informe, y aunque exclame *oh mares de mis cuatro litorales perdidos ${ }^{6}$ no puede evitar la pasión y forma. Alberti quiere domar el mar, como quiere domar sus poemas:

¡El ritmo, mar, el ritmo, el verso, el verso!

Reprime así la espontaneidad, igual que sus maestros en el tema mares/ríos: Gil Vicente, Machado, Garcilaso, Baudelaire, Juan Ramón Jiménez, Rubén Darío, Pedro Espinosa y Góngora. El deseo de domeñar llega al delirio:

\section{Quiero, mar, que en mi dia, que en esa misma hora, te mueras tú también.}

«El agua verdadera era el agua delimitada (...); no era el agua loca, el agua vaga, el agua rezumante, estancada o fluyente, sino el mineral recogido en el fondo de la jarra, humanizada por su recipienten ${ }^{7}$. Notemos que el agua delimitada por la jarra (mencionada por Sartre respecto a Baudelaire) lo está también en Alberti por la Bahía; porque ésta es asimismo un resultado cultural y no sólo natural.

El título del libro - Pleamar- nos remite a una vieja creencia: ¿La relación que el pueblo ha establecido entre la marea y la muerte.: Los antiguos creían que los enfermos no morían mientras hubiese marea alta, y actualmente en muchos sitios se sigue esta tradición. Limitándonos a España, hallamos lo que sigue. Filostrato en la Vida de Apolonio, $V, I I$, dice: «Apolonio confirma su opinión por una observación que le proporcionaron los enfermos de Gades: durante todo el tiempo de flujo el aliento no abandona a los moribundos, lo cual no se explica sino porque entonces el viento se extiende por la tierra» ${ }^{8}$. Posidonio tomó de los gaditanos una serie de observaciones, que luego repite Estrabón, sobre la relación entre

6 Alberti me confesó que al poetizar sobre este o aquel mar, siempre tenía en la mente su mar gaditano. Vid. Jorge Guillén y Rafael Alberti hablan del 27, entrevista concedida al autor de estas páginas y publicada por la U.N.E. D. de Albacete, Anuario de 1981.

7 SARTRE, Jean-Paul: Baudelaire, Buenos Aires, Losada, 1957, 2." ed., pág. 76.

3 Caro Baroja, Julio: La estación de amor (Fiestas populares de mayo a San Juan), Madrid, Ediciones Taurus, 1979, pág. 139. 
las mareas y los solsticios y equinoccios. Ya algunos autores clásicos advirtieron que dichas observaciones eran falsas, pero eso es lo de menos para nuestro propósito: es posible que Alberti oyera en su infancia esas historias entre la realidad y la leyenda, o bien las leyera en nuestros clásicos, porque en Pleamar nos dice:

48

Vivir en pleamar, seguir viviendo...

49

Nunca morir en bajamar, no, nunca...

Parece cierto que Alberti, a la hora de componer Pleamar, no ignoraba que las fiestas de mayo y del solsticio de verano nos remiten a la exaltación de «la vida de los hombres, de los animales y de las plantas, con el agua y el fuego como principios» 9 . Transcribo los últimos versos del poema «Hemisferio austral»:

Una vez más al cielo y de la mano demos el corazón hecho mirada, en tanto que la luz llora aqui en grano lo que alli en cabellera deshelada.

Es el descenso del verano...

Pero las citadas fiestas nos remiten también a la fertilidad, que en el caso de Pleamar se manifiesta asimismo en la creación poética:

$A$ veces, el poeta armado de rebenque y cólera apretada, separando tinieblas, largas, inacabables, feroz, corre a la caza de su Musa: -iOh ramera! ¿En donde estabas, di? ¿Qué hacias, que no acudes cuando te necesito?

I Ibidem, pág. 303. 
La ilusión de soñarme siquiera un olvidado Albertl en los rincones del Museo del Prado.

R. A.

A la pintura es una especie de teoría poética sobre las formas, disfrazada de autobiografía. Alberti piensa, como Horacio, que la pintura es poesía que habla y la poesía, pintura locuaz; doctrina que se difunde por los comentaristas italianos del Cinquecento. Nuestro poeta quiere llegar definitivamente a una estética equilibrada:

Llueve la luz, y sin aviso ya es una ninfa fugitiva que el ojo busca clavar viva sobre el espacio más preciso.

$(* 1917 x$.

Alberti vuelve a su primera dedicación - la pintura - en el momento de su madurez poética y ya para siempre simultanea sus dos pasiones.

Lo más sorprendente de $A$ la pintura es la recreación de formas nuevas y distintas para cada pintor, objeto, etc. No voy a citar los innumerables elementos que Alberti ha tomado de sus obras anteriores, pero ahora los reordena según el espacio pictórico. Parece que ha intuido el pensamiento de Jakobson: *Si en pintura, en arte figurativo, se puede tener todavía la ilusión de una finalidad objetiva y absoluta a la realidad, la cuestión de verosimilitud «natural" (según la terminología de Platón) de una expresión verbal, de una descripción literaria, estă evidentemente desprovista de sentido. ¿Se puede plantear la cuestión del grado de verosimilitud de tal o cual clase de tropo poético? ¿Se puede decir que tal metáfora o metonimia es objetivamente más realista que tal otra? Incluso en pintura el realismo es convencional, es decir, figurativo ${ }^{10}$. La realidad ilusoria que es la pintura se expresa por otra no menos inverosímil: la poesía. Tomemos sólo unos ejemplos:

¡El mar, tal vez el mar, pero de piedra!

Ya no eres lino, plano humilde, tela.

( $\ltimes$ Miguel Angelm.)

Ya eres barco celeste, brisa, vela.

A ti, ángel salvador de la Pintura.

(*Al lienzo*.)

10 Cit. por Caparrós, J. D., en Critica literaria, Madrid, U. N. E. D., 1978, 7/XX, 2. 
A ti, premeditada fantasía, diosa avara de cálculo, ladrona

del pleno espacio puro que corona

la inspiración de la sabiduría.

( «A la composición».)

Quizás Alberti conociera Della pintura, de Leonardo. Varias de las reflexiones del italiano las encontramos en el citado poemario de Alberti, y el soneto "A la perspectiva" se cierra con un aforismo de Da Vinci:

A ti, brida y timón de la pintura.

¡Qué consuelo sin nombre no perder la memoria!

R. A.

Una vez descartada la restauración inmediata de la libertad en España, no tiene sentido la esperanza, por eso Alberti se refugia en la nostalgia. Me parece ver en «Nuevos retornos del otoño una réplica al optimismo predicado por los dirigentes republicanos en general y especialmente por los comunistas:

Sonreid. Sed alegres. Cantad la vida nueva.

Pero yo sin vivirla, icuántas veces la canto!

iCudintas veces animo ciegamente a los tristes,

diciéndoles: Sed fuertes, porque vuestra es el alba!

Estamos ante los Retornos de lo vivo lejano, obra escrita a partir de $1948^{\prime \prime}$. El poeta sabe que es imposible la vuelta: nada será ni es como antes; por eso inventa un mundo nuevo: el retorno de lo vivo lejano. Los elementos que nos comunica resultan triviales si los comparamos con los de obras anteriores. Lo que ocurre es que se han cargado de símbolos: ha simbolizado su propia obra. Como esta afirmación puede parecer confusa, paso a explicarme.

Alberti sabe que está «en medio del camino de la vida». Detrás queda una experiencia plena de pasión y formas, delante está el futuro más que incierto. Pero el poeta canta con palabras: aquí no

11 La mayoria de los Retornos... recogidos en las Poesias completas fueron escritos entre 1948 y 1956. 
vamos a distinguir las suyas y las ajenas: el autor no inventa un vocabulario, sino que lo descubre. El descubrimiento de Retornos consiste en convertir en biografía lo que fue autobiografía. Antes dije que los elementos que nos comunica son triviales: aquí empleo el término con la tercera acepción del Diccionario de la R.A.E.: "Común y sabido de todos." El lector de Alberti -poeta éste autobiográfico donde los haya- conocía la "historia» de Retornos... Nuestro poeta, al volver a "relatarnos» su vida y obra ya pasadas, las está convirtiendo en símbolos.

Pero ¿qué entendemos por símbolo? Yo lo definiría por oposición al signo linguístico, hecho que, por otra parte, no escapó a Ferdinand de Saussure ${ }^{12}$. Sin embargo -y que no resulte paradójicoexisten -como señala Julia Kristeva - estrechas conexiones entre el símbolo y el signo. Pero resolvamos antes la aparente paradoja.

No me estoy refiriendo a los símbolos convencionales, que tanto abundan en épocas y autores determinados y con los que se pueden componer diccionarios ${ }^{13}$, sino a los que nacen de la confianza en las posibilidades expresivas de los signos y, al mismo tiempo, de la desconfianza de que éstos lo hayan dicho todo ${ }^{14}$.

Alberti sabe que la recurrencia - tanto fónica como semántica ${ }^{15}$ - constituye un fenómeno esencial en el discurso lírico, que tiene carácter estático frente al dinámico de la prosa. Por otra parte, el poeta se sabe dominador de las recurrencias fónicas, que intenta atenuar a favor de las semánticas. No insinúo que prescinda de las primeras, sin las cuales no hay poesía, sino que predominan las que insisten en los componentes de sentido ${ }^{16}$.

12 «El símbolo tiene por carácter no ser nunca completamente arbitrario; no está vacio: hay un rudimento de vinculo natural entre el significante y el significados» (Curso de linüistica general, Buenos Aires, Losada, 1967, 6." ed., pág. 131). Una aclaración: Saussure afirma antes: «Se ha utilizado la palabra símbolo para designar el signo linguístico, $o$, más exactamente, lo que nosotros llamamos significante.»

13 Por ejemplo, el de J. E. Cirlot. Notemos que los símbolos propios de un autor también se pueden aislar. En $\times$ La relación metal-muerte en la poesía de Federico García Lorca», de Ramón Xirau, leemos: sLa muerte por el metal, agresiva, violenta, se convierte en símbolon, apud Mito y poesia, Universidad Autónoma de México, 1973, págs. 109-124.

14 En esta dualidad que puede parecer perogrullesca, se mueve buena parte de la poesía de Alberti.

15 No es éste el lugar de estudiar las recurrencias fónicas. Sólo señalaré una que me parece capital: la que consiste en repetir unidades fónicas isosilábicas, en este caso el generoso empleo de los alejandrinos: tendencia generalizada en los versolibristas españoles y franceses.

16 Tampoco intento introducir de soslayo la dicotomía 'recurrencia fónica'/ 'recurrencia semántica'. 
Antes me referí a la oposición signo/símbolo. Si bien es cierto que el símbolo poético se expresa con signos, no lo es menos que éstos se convierten en "cosas» y al simbolizar - como tales- "desbordan por todas partes el sentimiento que las ha suscitado".

Pero, ¿y las estrechas relaciones entre el símbolo y el signo? En este caso, el signo es toda su obra anterior, que se convierte así en "diccionario de símbolos". Transcribo a continuación los primeros versos de Retornos...:

También estará ahora lloviendo, neblinando en aquellas bahias de mis muertes, de mis años aún vivos sin muertes.

(«Retornos de una tarde de lluvia».)

«Estará lloviendo» significa la prolongación de la acción. Pero observemos que ha dividido la perifrasis con la introducción de «ahora», división que se da también en la lengua coloquial. La extrañeza llega con el final del segundo verso: "de mis muertes". A cualquier lector de Alberti no le extrañaría «días» 17, "sueños», "mi infancia»... La extrañeza se intensifica en el tercer verso: «de mis años aún vivos sin muertes», pero desaparece si recordamos. Dicho de otra forma: quizá la contemplación de la lluvia $\longrightarrow$ simplemente el recuerdo- trae a la memoria de Alberti el sueño vivo de xuna" tormenta, celebrada por los niños con júbilo y miedo. La recurrencia semántica se establece entre el tiempo en que está viviendo -el de la escritura del poema- y el recuerdo feliz, perdido por "mis muertes». La lluvia (= felicidad) lo introduce en un mundo nostálgico: ya no leemos tristeza: su antigua ciudad es azul con barandales blancos... Pero el pasado paradisiaco -introducido por un futuro, que no es más que un pasado continuado- se expresa por futuros hipotéticos:

Te asomarias tú, vejez blanca, saliéndote de tus templadas sábanas de nietos $y$ ojos dulces.

Saldria yo con Agustín, con José Ignacio y con Paquillo, el hijo del cochero, a buscar caracoles por las tapias.

( $\star$ Retornos de una tarde de lluviaw.)

17 Dejemos aparte la rima interna fácil que se hubiera producido en este caso. Alberti la habria evitado. 
Alberti ha seleccionado el futuro hipotético porque, al ser un tiempo imperfecto, la terminación de la acción queda indeterminada. Los futuros del pasado («asomarías», «saldría») nos remiten al engañoso futuro inicial. Pero el poeta nos desengaña en el mismo poema:
Reclino la cabeza,
llevo el oido al hoyo de la mano
para pasar mejor lo que de lejos
con las olas de alli, con las de allá,
fatigando la orilla de castillos,
de bañadas ruinas y escaleras
chorreando me viene. Oigo un galope
con los pies destrozados en el agua.

Porque al relacionar el futuro hipotético con el presente (*reclino», «llevo", «oigo») nos lleva a acciones borrosas, y los anhelados "paraísos sin humo" son imposibles:

Se murió el mar, se murió el mar, murieron con él las cosas que llegaron. Quedan, ya solo quedan, ioyes?, una conversación confusa, un errabundo coloquio sin palabras que entender, un temido, un invasor espanto a regresar sin ojos, a cerrarlos sin sueño.

Si el poema hubiera terminado en el puntual "murió", quedaría resaltado estilísticamente el contraste entre el pasado y el presente. Pero Alberti - utilizando el presente aquedan - nos conduce a un futuro: regresar sin ojos, esto es, ha detenido el pasado feliz: retornar es imposible.

La mayor parte de los recuerdos expresados en Retornos... habían sido utilizados por el autor en los distintos géneros de su producción anterior: poemas, dramas, La arboleda perdida, Imagen primera de... En la primera sección de Retornos selecciona los siguientes: juegos infantiles, estancia en el colegio y sus escapadas, veladas en las que los seis hermanos oían a su madre tocar el piano, visita a Juan Ramón Jiménez, primera vocación, Museo del Prado (siempre en Alberti, el Museo del Prado). La sustancia de contenido, pues, está perfectamente delimitada, y a veces concretada en la forma de expresión anterior. Pero Alberti reordena ambas cosas: la familia ya no recibe sus improperios, como en algunas piezas de la guerra civil, y en el poema subtitulado «J. R. J.» (Juan Ramón Jiménez) no asoma ningún rasgo neurótico de los que apa- 
recían en Imagen primera de... ${ }^{18}$. Además, ha eliminado anécdotas que en la prosa tenian sentido. Por otra parte, el poema al que me estoy refiriendo, "Retornos de un día de cumpleaños (J.R. J.)", selecciona o intensifica elementos usados para crear un mundo nuevo poéticamente pero sin retorno:

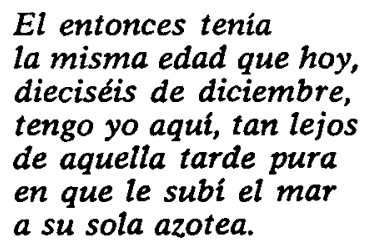

A veces no es la sombra del Paraíso lo que se ha perdido, sino la sombra de la sombra del Paraíso ${ }^{19}$ :

Algún día quizá, seguramente alguien
(alguien a quien siquiera pueda ofrecer tal nombre)
se acordará de mí pensándome tan lejos
y dirá lo que yo, si hubiese retornado.

Aqui estás, ya has venido, con más noche en la frente.

Llegas de caminante, de romero a tu patria.

Los lugares que hiciste, las horas que creaste, pasados todavia de tu luz y tu sombra, salen a recibirte.

( «Retornos de un día de retornos».)

Alberti quiere «fijar su obra, detenerla para que sea una realidad perdurable frente al triste presente; pero simultáneamente Retornos... no es su testamento poético, como se puede comprobar leyendo el que lleva por título «Retornos de una isla dichosa».

18 Sin embargo, de la prosa «Imagen primera de Juan Ramón Jiménez" pasan al poema materiales levemente rectificados. En la primera columna doy los de «Imagen...* y en la segunda los de *Retornos de un día de cumpleaños (J. R. J.)»: Entre las madreselvas y campanillas Azotea alta (Alta azotea en A. P.) Voz suave, opaca Entre madreselvas y jazmines Sola azotea

Opaca voz

19 Recordemos que Alberti escribio lo siguiente en el primer poema de Sobre los angeles:

$$
\begin{aligned}
& \text { ¿Adónde el Paraiso, } \\
& \text { sombra, tú que has estado? }
\end{aligned}
$$

Quizá Aleixandre tomara de aquí el título para una de sus obras más célebres. 
La segunda parte del libro canta los retornos del amor. Esta sección constituye el conjunto de poemas amorosos más bellos de Alberti. ¿Y por qué los más bellos? Yo creo que por la "precisión», es decir, la ausencia de retoricismo-del que adolecen algunos Sonetos corporales-, y por el dramatismo, que tiene su origen en lo que venimos llamando retorno.

La oposición entre lo puntual y lo durativo se inicia en el primer poema de la serie, "Retornos del amor recién aparecido»:

Cuando tú apareciste, penaba yo en la entraña más profunda de una cueva sin aire y sin salida.

Las oposiciones citadas organizan todo el poema: «Braceaba en lo oscuro...», «sobre mí derramaste tus cabellos / y ascendí al sol y vi que eran la aurora...* Resulta que se suele cantar lo que se ha perdido; quien tiene, goza, no canta:
Mas las palabras, ¿dónde?
Las palabras no llegan. No tuvieron espacio
en aquel agostado nocturno, no tuvieron
ese mínimo aire que media entre dos bocas
antes de reducirse a un clavel silencioso.

De poco sirve que termine así el poema: «Es que siempre en la noche del amor pasa un río.» Estamos ante una vana esperanza y Alberti lo sabe. Poeta autobiográfico, convierte las experiencias en biografía: «La edad de oro del amor venía.» Vela en este tema la realidad que tantas veces descubrió al desnudo. Veamos: al estallar la guerra civil, Alberti y María Teresa León se encontraban en Ibiza, fueron perseguidos y se refugiaron en los montes hasta ser liberados por la flota republicana. A esta situación se refiere el poeta en « Retornos del amor fugitivo en los montes»:

Iba el amor a ser dichoso. Era

la juventud con cinco toros dentro.

Iba el ardor a arder en los racimos.

Era la sangre un borbotón de llamas.

Era la paz para el amor. Venía

la edad de oro del amor. Ya era.

No entremos en el pudor de tradición petraquista con el que se impregna casi toda la lírica erótica española. Creo que Alberti vela la referencia por dos motivos: el goce amoroso es irrepetible $y$, pasada la juventud, «los campos no ascienden a jardines». 
La tercera parte de los Retornos... es miscelánea: la guerra civil, la libertad, su perro Niebla, el pueblo español y algunos poetas. La guerra española es nombrada «sombra maldita». Me parece ver aquí un reflejo machadiano («Será difícil, madre, volver a ti? Feroces / somos tus hijos...») y de la resolución del partido comunista sobre la reconciliación nacional:

Júntanos, madre. Acerca esa preciosa rama tuya, tan escondida, que anhelamos asir, estrechar todos, encendiéndonos en ella como un único fruto de sabor dulce, igual.

Alberti se propuso desde sus días iniciales que cada una de sus obras fuese enfocada como una unidad, casi un cerrado círculo en el que los poemas, sueltos y libres en apariencia, completaran un todo armónico, definido. Sin embargo, Retornos de lo vivo lejano es una obra abierta. Creo que afortunadamente, de lo contrario hubiera sido su definitivo testamento poético, pues, no lo olvidemos, esta obra es la simbolización de su producción anterior.

Porque por ti soy tú y seré por ti solo lo que fuiste y serás para siempre en el tiempo.

Estos dos versos cierran el poema «Retornos de la invariable poesía». Alberti ya no se siente poeta, sino poesía y, como tal, perdurable. 